\title{
Which Strategies Improve Physicians' Experience with Health Information Technology?
}

\author{
Jacqueline Haskell $^{1}$ Brittany Mandeville ${ }^{2}$ Emily Cooper ${ }^{1}$ Rebekah Gardner ${ }^{1,3}$ \\ ${ }^{1}$ Healthcentric Advisors, Providence, Rhode Island, United States \\ ${ }^{2}$ Clarion Healthcare, Boston, Massachusetts, United States \\ Address for correspondence Jacqueline Haskell, MS, Healthcentric \\ 3 Department of Medicine, Warren Alpert Medical School of Brown \\ University, Providence, Rhode Island, United States \\ Advisors, 235 Promenade Street, Suite 500, Providence, RI 02908, \\ United States (e-mail: jhaskell@healthcentricadvisors.org).
}

ACI Open 2021;5:e47-e53.

\section{Abstract}

Keywords

- electronic health records and systems

- workflows and human interactions

- medical informatics

- burnout

- professional

- occupational stress
Objectives While electronic health records (EHRs) have improved billing efficiency and note legibility, they may also disrupt clinical workflows, affect patient interactions, and contribute to physician burnout. This study aimed to identify effective strategies, as reported by physicians, to mitigate these EHR shortcomings.

Methods The Rhode Island Department of Health administers a health information technology (HIT) survey biennially to all physicians in active practice statewide. The 2019 survey asked physicians about strategies implemented personally or by their practice to improve their experience working with HIT. Physicians who identified at least one strategy were then asked if each implemented strategy was "actually useful." Results The 2019 survey was administered to 4,266 physicians, with a response rate of $43 \%$. Both office- and hospital-based physicians most commonly reported that their practices had implemented voice-recognition dictation software (48 and 68\%, respectively). Office- and hospital-based physicians identified self-care as the most commonly implemented personal change (48 and $47 \%$, respectively). However, $26 \%$ of officebased and $15 \%$ of hospital-based physicians reported reducing clinical hours or working part-time to improve their experience working with HIT. The strategies identified as "actually useful" varied by practice setting and were not always the most widely implemented approaches.

Conclusion Most physicians reported that both they personally and their practices had implemented strategies to improve their experience with HIT. Physicians found some of these strategies more helpful than others, and the strategies identified as most useful differed between office- and hospital-based physicians. From a workforce and access perspective, prioritizing strategies that physicians find "actually useful" is critical, as many physicians in both settings reported reducing clinical hours to improve their experience. received

October 15, 2020 accepted after revision May 11, 2021
DOI https://doi.org/

$10.1055 / \mathrm{s}-0041-1731338$

ISSN 2566-9346.
(C) 2021. The Author(s).

This is an open access article published by Thieme under the terms of the Creative Commons Attribution License, permitting unrestricted use, distribution, and reproduction so long as the original work is properly cited. (https://creativecommons.org/licenses/by/4.0/)

Georg Thieme Verlag KG, Rüdigerstraße 14, 70469 Stuttgart, Germany 


\section{Introduction}

Nearly all hospitals and most physician offices have implemented electronic health records (EHRs)., ${ }^{1,2}$ EHRs have had a positive impact on many aspects of medicine, including improved administration efficiency and note legibility. ${ }^{3}$ Some practices in the advanced stages of EHR implementation have experienced improved patient outcomes, including fewer hospital admissions, ${ }^{4,5}$ and a systematic review found that EHR-based computerized decision support systems may lead to improvements in morbidity outcomes. ${ }^{6}$ However, some studies have demonstrated that EHR implementation is not robustly associated with improvements in care quality. ${ }^{7,8}$

Many physicians see the value of EHRs and most would not want to return to paper-based medical records. ${ }^{9}$ However, despite these positive outcomes, EHRs have been linked to lower patient satisfaction and a significant increase in staff turnover. ${ }^{10,11}$ EHRs may also disrupt clinical workflows and negatively affect patient interactions. ${ }^{9,12-14}$ Importantly, the use of EHRs has been associated with physician burnout, ${ }^{15,16}$ which may be mitigated by a high level of EHR usability. ${ }^{17}$

Researchers have studied many potential interventions to improve the physician experience of working with the EHR. Most of the relevant literature focuses on organizationdirected interventions. Strategies to improve physician satisfaction include sharing EHR tasks with other members of the care team, ${ }^{18}$ scheduling "desk top slots" to allow time for inbox management during the work day, ${ }^{19}$ and hiring scribes to assist with documentation and clerical tasks. ${ }^{20}$ Other interventions have focused on improving efficiency, including "tap and go" logins ${ }^{21}$ and reducing the number of clicks through auto-filling information and eliminating unnecessary fields. ${ }^{22}$ EHR training has also been associated with more satisfaction and efficiency, such as personalized oneon-one training and interactive skills training. ${ }^{23,24}$ Other types of interventions to address physician burnout have focused on building physician resilience through mindfulness-based stress reduction, educational interventions, exercise, or a combination of these. ${ }^{25}$ However, two systematic reviews found that organization-directed interventions were more effective in reducing burnout than physician-directed interventions. $^{25,26}$

\section{Objective}

Improving physicians' experience with the EHR is of interest both at the physician level and at the organizational level. Successful EHR implementation includes considering how the technology "fits" into the existing practice workflow and into the workflow of the professionals providing care. ${ }^{27}$ Given the central role that EHRs play in most physicians' work, it is important to understand which strategies effectively reduce technology-related stress. This study aimed to identify effective strategies, as reported by physicians, to improve the clinical experience working with health information technology (HIT).

\section{Methods}

\section{Survey Administration}

The Rhode Island Department of Health (RIDOH) administers an HIT survey to all Rhode Island physicians in active practice. RIDOH administers the HIT survey as part of a legislatively mandated public reporting program. It uses the data to report clinician-level process measures relating to HIT adoption and use. The survey was distributed annually from 2009 to 2015 and every other year since $2015 .^{28-34}$ The survey is administered electronically by using an online survey platform. ${ }^{35}$

The 2019 survey was administered between April 22 and May 10. Hard copy survey notices were mailed to all 4,266 physicians licensed in Rhode Island, who were in active practice and located in Rhode Island, Connecticut, and Massachusetts. Email notices and up to two email reminders were sent to those who had an email address on file with RIDOH.

\section{Survey Questions and Respondent Characteristics}

The HIT survey asked physicians questions about their specialty, degree type (MD or DO), main practice setting (outpatient/office or inpatient/hospital), practice size (1-3 clinicians, 4-9 clinicians, 10-15 clinicians, 16 or more clinicians), whether they provide primary care, and whether they use an EHR. We grouped specialty responses into nine categories: emergency medicine, family medicine, internal medicine, medical subspecialties, obstetrics and gynecology, pediatrics, psychiatry, surgery (general and subspecialty), and other/unknown.

In collaboration with RIDOH, a multistakeholder group (including physicians, payers, researchers, and community members among others), recommended questions for inclusion in the 2019 survey. We report on a set of questions, asked only in the 2019 survey, about strategies implemented personally by physicians or by their practice to improve their experience working with HIT. The survey provided a list of practice-level strategies and asked respondents with EHRs the following: "please indicate if your 'practice' has implemented any of the following to try to improve your experience working with HIT." Physicians were able to select multiple strategies. Physicians who selected at least one strategy were then asked if each implemented strategy was "actually useful." Similarly, physicians with EHRs were shown a list of personal strategies and were asked: "please indicate if 'you' have implemented any of the following to try to improve your experience working with HIT." Again, physicians who selected at least one strategy were also asked if each implemented strategy was "actually useful." We chose not to define the term "actually useful" to avoid making the question stem overly long and to allow physicians to respond based on their own assessment of usefulness in this context. We piloted all new questions in the 2019 survey, including this set of questions, with a subset of physicians using cognitive debriefing to test question comprehension and the response process, as well as the face validity of the included constructs.

The lists of strategies were derived from prior research, including a recent study that used focus groups of 
ambulatory physicians to identify both organizational changes and personal strategies to address the challenges of using HIT. ${ }^{36}$ These focus groups included questions and probes about coping strategies that physicians had used to address stress from HIT, what they had done to improve their satisfaction or acceptance of HIT, and what would improve their ability to provide patient care using HIT. Based on the study's results, ${ }^{36}$ we developed two lists of strategies: (1) practice-level changes, such as recurring IT training and scheduled time blocks to complete desk work, and (2) personal-level changes, such as customizing the EHR and talking with colleagues to learn tips and tricks. The survey questions were piloted with a small group of clinicians for clarity and relevance and then refined based on physician feedback.

Additional survey questions provided insight into the level of other HIT and clinical support that the physicians received. One question asked respondents whether they work with a medical scribe, and another question asked respondents to indicate how often they receive assistance from someone in their practice in managing their inbox tasks, on a 5-point scale ("almost always," “often," “sometimes," “rarely," “never”). Respondents were also asked whether the availability and effectiveness of HIT-related technical support at their main practice site usually meets their needs.

\section{Analysis}

We analyzed a de-identified 2019 HIT survey dataset, available from RIDOH with a data use agreement, which also contains information on age and gender from RIDOH's licensure file. As the dataset was publicly available and deidentified, the analysis did not require approval by an institutional review board. We used summary statistics, including means and percentages, in our analysis and stratified respondents by their self-reported main practice setting. Chi-square tests were conducted by using SAS. Respondents were compared with nonrespondents by using a previous analysis of available demographic information from the RIDOH's licensure file (age, gender, and specialty). ${ }^{37}$

\section{Results}

\section{Respondent Characteristics}

Among 4,266 physicians who were sent the 2019 survey link, 1,835 responded (response rate of $43.0 \%$ ). Over one-third (37.4\%) of respondents were females and $42.2 \%$ were between the ages of 29 and 50 years. Two-thirds practiced primarily in an outpatient setting (67.2\%), and about onethird worked with 16 or more clinicians at their main practice site (35.3\%). Among the sample, 31.1\% reported being a primary care physician. Most physician respondents reported using an EHR (92.5\%) (-Table 1).

Respondents and nonrespondents had similar distributions of gender and most specialties. ${ }^{37}$ Compared with nonrespondents, a greater percentage of respondents were pediatricians ( 9 vs. $6 \%, p=0.001$ ) and psychiatrists ( 7 vs. $4 \%, p<0.001$ ). Respondents were also older than nonrespondents, with $42.2 \%$ of respondents aged 29 to 50 years, compared with $53.0 \%$ of nonrespondents $(p<0.001)$.
Table 1 Characteristics of the physician respondents $(N=1,835)$

\begin{tabular}{|c|c|}
\hline Characteristics & $n(\%)$ \\
\hline \multicolumn{2}{|l|}{ Age } \\
\hline $29-50$ & $775(42.2 \%)$ \\
\hline $51-64$ & $699(38.1 \%)$ \\
\hline $65-92$ & $361(19.7 \%)$ \\
\hline Female & $686(37.4 \%)$ \\
\hline \multicolumn{2}{|l|}{ Main practice setting } \\
\hline Office/outpatient & $1,234(67.2 \%)$ \\
\hline Hospital/inpatient & $601(32.8 \%)$ \\
\hline \multicolumn{2}{|l|}{ Practice size } \\
\hline 1-3 clinicians & $451(24.6 \%)$ \\
\hline 4-9 clinicians & $541(29.5 \%)$ \\
\hline $10-15$ clinicians & $187(10.2 \%)$ \\
\hline 16 or more clinicians & $648(35.3 \%)$ \\
\hline Primary care physician $^{a}$ & $571(31.1 \%)$ \\
\hline \multicolumn{2}{|l|}{ Specialty $^{\mathrm{b}}$} \\
\hline Emergency medicine & $73(4.0 \%)$ \\
\hline Family medicine & $132(7.2 \%)$ \\
\hline Internal medicine & $371(20.2 \%)$ \\
\hline $\begin{array}{l}\text { Internal/family medicine and } \\
\text { pediatric subspecialty }\end{array}$ & $159(8.7 \%)$ \\
\hline Obstetrics and gynecology & $69(3.8 \%)$ \\
\hline Pediatrics & $159(8.7 \%)$ \\
\hline Psychiatry & $124(6.8 \%)$ \\
\hline Surgery (general and subspecialty) & $149(8.1 \%)$ \\
\hline Other/unknown $^{\text {d }}$ & $599(32.6 \%)$ \\
\hline Use of EHR & $1,697(92.5 \%)$ \\
\hline
\end{tabular}

Abbreviation: EHR, electronic health record.

aSurvey respondents who replied "yes" to the question: do you provide primary care?.

bSurvey respondents were instructed to select their primary specialty from a list; specialties were then grouped into nine categories.

'Survey respondents were included in this category if they selected a medical subspecialty (e.g., cardiology, endocrinology, and gastroenterology).

${ }^{\mathrm{d}}$ Survey respondents were included in this category if they chose not to select a specialty or if their specialty was not among the other eight categories (e.g., pathology, radiology, and dermatology).

Note: Column percentage total may not sum to 100 due to missing responses.

\section{Practice-Level Strategies to Improve Experience with Health Information Technology}

Office-based physicians most commonly reported that their practices had implemented voice-recognition dictation software $(48.1 \%)$, printers in the clinical area (42.9\%), and staff support with EHR tasks (35.9\%) to improve their HIT experience (-Table 2). Among hospital-based physicians, the most commonly implemented strategy was also voice-recognition dictation software (68.0\%), followed by badge/fingerprint 
Table 2 Percentage of physicians who indicated that their practice or they personally had implemented each strategy to improve their experience with health information technology

\begin{tabular}{|l|l|l|l|}
\hline Strategy & $\begin{array}{l}\text { Office based } \\
(\boldsymbol{n}=\mathbf{1 , 0 9 0 )}\end{array}$ & $\begin{array}{l}\text { Hospital based } \\
(\boldsymbol{n}=\mathbf{6 0 0})\end{array}$ & $\boldsymbol{p}$-Value \\
\hline Practice-level changes & & & \\
\hline Badge or fingerprint login & $20.9 \%$ & $50.7 \%$ & $<0.001$ \\
\hline Printers in room or clinical area & $42.9 \%$ & $45.3 \%$ & 0.342 \\
\hline Recurring IT training, including one-on-one & $15.0 \%$ & $18.5 \%$ & 0.066 \\
\hline Reducing the number of clicks for common EHR tasks & $10.5 \%$ & $9.2 \%$ & 0.397 \\
\hline Scheduled time blocks to complete desk work & $16.6 \%$ & $2.7 \%$ & $<0.001$ \\
\hline Staff support with documentation & $16.5 \%$ & $12.5 \%$ & 0.027 \\
\hline Staff support with EHR tasks & $35.9 \%$ & $10.2 \%$ & $<0.001$ \\
\hline Touchscreen functionality & $12.8 \%$ & $6.5 \%$ & $<0.001$ \\
\hline Voice-recognition dictation software & $48.1 \%$ & $68.0 \%$ & $<0.001$ \\
\hline Other & $1.7 \%$ & $0.8 \%$ & 0.357 \\
\hline None & $15.2 \%$ & $9.3 \%$ & 0.001 \\
\hline Personal changes & & & \\
\hline Customizing the EHR (e.g., shortcuts) & $41.7 \%$ & $36.8 \%$ & 0.053 \\
\hline EHR training refresher courses & $3.8 \%$ & $2.7 \%$ & 0.233 \\
\hline More concise notes & $39.3 \%$ & $35.2 \%$ & 0.096 \\
\hline Reduction of clinical hours or working part-time & $26.2 \%$ & $14.7 \%$ & $<0.001$ \\
\hline Self-care (e.g., exercise, meditation, sleep) & $47.9 \%$ & $47.3 \%$ & 0.827 \\
\hline Strict work/life boundaries (e.g., setting limits on EHR use at home) & $28.9 \%$ & $30.7 \%$ & 0.446 \\
\hline Talking with colleagues about the challenges & $36.1 \%$ & $35.7 \%$ & 0.874 \\
\hline Talking with colleagues to learn tips and tricks & $38.3 \%$ & $44.3 \%$ & 0.017 \\
\hline Other & $3.4 \%$ & $1.5 \%$ & 0.022 \\
\hline None & $13.7 \%$ & $13.8 \%$ & 0.926 \\
\hline
\end{tabular}

Abbreviations: EHR, electronic health record; IT, information technology.

Note: This table includes 1,690 physicians who reported using EHRs and who selected at least one answer to the questions about practice-level or personal strategies.

login (50.7\%). Voice-recognition dictation software and badge/fingerprint login were more commonly implemented among hospital-based physicians $(p<0.001)$, while higher proportions of office-based physicians' practices had implemented staff support with documentation $(p=0.027)$ and EHR tasks ( $p<0.001)$, touch screen functionality $(p<0.001)$, and scheduled time blocks to complete desk work $(p<0.001)$ (-Table 2).

The practice changes identified as "actually useful" by the highest proportion of office-based respondents were staff support with EHR tasks, scheduled time blocks to complete desk work, and staff support with documentation (-Fig. 1). The change identified as "actually useful" by the highest proportion of hospital-based respondents was touchscreen functionality, followed by printers in the clinical area and staff support with documentation. Higher proportions of office-based physicians identified staff support with EHR tasks $(p<0.001)$ and recurring IT training $(p=0.047)$ as useful changes, while touch screen functionality was identified as useful by a higher proportion of hospital-based physicians $(p=0.001)$.

\section{Personal Strategies to Improve Experience with Health Information Technology}

Among both office- and hospital-based physicians, the most common strategy that physician respondents had personally

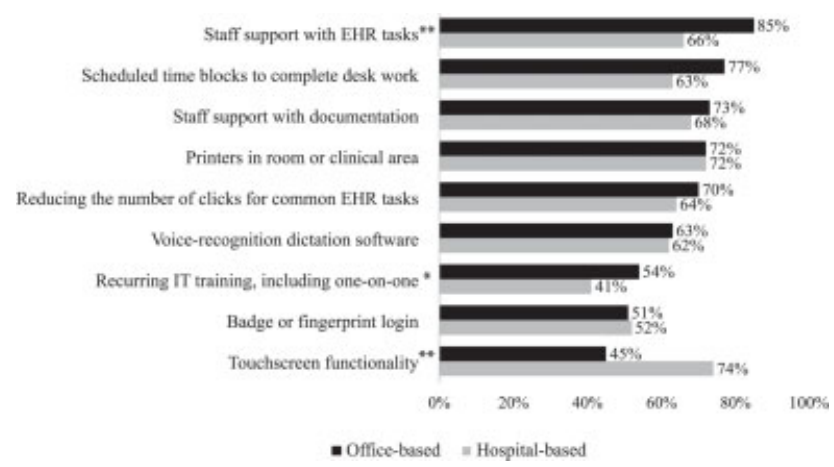

Fig. 1 Percentage of physicians who identified each practice-level strategy as "actually useful" in improving their experience with health information technology. Asterisks indicate significant differences between office-based and hospital-based physicians at $p<0.05\left({ }^{*}\right)$ and $p<0.01\left(^{* *}\right)$. IT, information technology; EHR, electronic health record. 


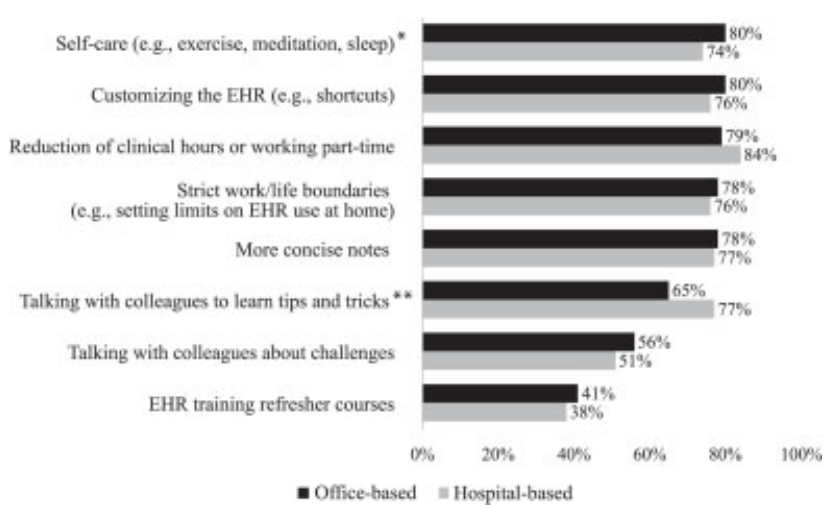

Fig. 2 Percentage of physicians who identified each personal strategy as "actually useful" in improving their experience with health information technology. Asterisks indicate significant differences between office-based and hospital-based physicians at $p<0.05\left({ }^{*}\right)$ and $p<0.01$ $\left.{ }^{(* *}\right)$. EHR, electronic health record.

implemented was self-care, such as exercise or meditation (47.9 and $47.3 \%$, respectively; - Table 2). Notably, $26.2 \%$ of office-based and $14.7 \%$ of hospital-based physicians reported reducing clinical hours or working part-time to improve their experience working with HIT, with a significantly higher proportion of office-based physicians reporting this strategy $(p<0.001)$. Among the respondents who selected "other" and provided open-ended responses, 15 physicians described changes to their work schedule or position, such as switching jobs, leaving primary care, seeing fewer patients, taking days off, and planning for earlier retirement.

The changes identified as "actually useful" by the highest proportion of office-based physicians were self-care, customizing the EHR, and reduction of clinical hours or working part-time; the highest proportion of hospital-based physicians identified reducing clinical hours or working part-time, talking with colleagues to learn tips and tricks, and writing more concise notes as "actually useful" strategies (-Fig. 2). Self-care was identified as useful by a higher proportion of office-based than hospital-based physicians $(p=0.050)$, while a higher proportion of hospital-based physicians found it useful to talk with colleagues to learn tips and tricks $(p<0.001)$.

\section{Clinical and Technical Support}

Among physician respondents using EHRs, 9.9\% worked with a medical scribe at their main practice site. A minority of physicians responded that they received assistance with EHR inbox tasks, with $35.1 \%$ of office-based physicians and $11.4 \%$ of hospital-based physicians reporting that they "always" or "often" receive this support. Most physicians indicated that the availability of technical support usually meets their needs (76.5\% of office-based and $80.7 \%$ of hospital-based physicians) and that the support is effective (76.2\% of officebased and $81.1 \%$ of hospital-based physicians).

\section{Discussion}

We found that most physicians had implemented strategies to improve their experience working with HIT, both at the practice level and on a personal level, including a quarter of the office-based sample who reported that they had reduced clinical hours for this reason. Physicians found some of the strategies more helpful than others, although office- and hospital-based physicians did not always agree on which strategies were the most useful. Some of the strategies identified by a majority of physicians as "actually useful" were not widely implemented.

Across practice-level and personal changes, physicians reported that useful strategies included improvements to the usability of the EHR (e.g., customizing the EHR touch screen functionality) and additional staff support with EHR tasks and documentation. While our survey asked about the effect of these strategies on physicians' experience with HIT, not burnout, two recent systematic reviews of organizationdirected workplace interventions for physician burnout also found a positive impact from interventions that focused on workflow, team-based care, documentation, EHR optimization, and EHR tasks. ${ }^{38} \mathrm{~A}$ randomized controlled trial found that documentation assistance from scribes significantly improved overall physician satisfaction. ${ }^{20}$ In addition to the strategies included in our survey, other organizationdirected interventions have been found to be effective in reducing the burden of EHR tasks, such as a quality improvement intervention to reduce prescribing tasks and an enhanced EHR text paging system to improve communication related to the EHR. ${ }^{39}$

Most physicians in our study indicated that technical support is usually available and that this support is effective. While technical support has been previously identified as a barrier to EHR adoption and use, ${ }^{40}$ this did not appear to be a key concern in our sample. Clinical support is less readily available, with a minority of physicians responding that they "always" or "often" received assistance with EHR inbox tasks, while many physician respondents found additional staff support with EHR tasks and documentation to be a useful practice-level strategy. A growing body of literature reinforces the importance of support with documentation and inbox tasks. ${ }^{13,41-43}$

Some of the physicians in our sample reported reducing clinical hours or working part time to improve their experience working with HIT (26\% of office-based and $15 \%$ of hospital-based physicians). This result is consistent with findings from a recent survey of U.S. physicians, where $19.8 \%$ of physicians responded that they would likely or definitely reduce their clinical hours during the next 12 months and $26.6 \%$ reported that they would likely or definitely leave their current practice during the next 24 months. ${ }^{44}$ In that study, dissatisfaction with the EHR was significantly associated with the intent to reduce clinical work hours and leave current practice. Similarly, a study of physicians in a multispecialty practice found that physicians receiving a higher-than-average number of EHR in-basket messages had a $38 \%$ higher probability of intending to reduce clinical time. ${ }^{45}$ Given this link between EHR burden, physician burnout, and turnover, there is a business case for implementing HIT-related strategies that do not rely on physicians reducing their clinical hours. ${ }^{46}$ 
Many physician respondents had implemented self-care activities (47.9\% of office-based and $47.3 \%$ of hospital-based physicians), and a majority of these physicians found this strategy to be useful. However, in their open-ended responses, several physician respondents found the focus on personal strategies, particularly self-care, to be "insulting," "demeaning," or "useless." Multiple respondents indicated that HITrelated stress and EHR burden should be addressed at an organizational or policy level rather than tasking physicians to engage in self-care to improve their work experience.

While our study has several strengths, including use of a statewide sample, inclusion of a range of specialties, and the presence of different EHR vendors, the findings should be considered in the context of the following limitations. As this is a study of physicians' survey responses, it is subject to selfreporting bias. The usefulness of strategies is based on physicians' perceptions rather than any measurement of stress levels before and after implementing a strategy. Several factors may also limit the generalizability of our findings. The survey was administered in a single state. While the response rate is good for a physician survey, we noted some differences between respondents and nonrespondents, including a higher proportion of pediatricians and psychiatrists among the respondents. While pediatricians may generally have higher survey response rates than other physicians, ${ }^{47}$ it may also be that physicians whose patients are most affected by potentially intrusive technology are more likely to complete an HIT survey. In addition, since we administered the survey electronically, physicians who are more comfortable with computers may have been more likely to respond.

\section{Conclusion}

From a workforce and access perspective, prioritizing strategies that physicians find "actually useful" is critical, as many physicians in both inpatient and outpatient settings reported reducing clinical hours to improve their experience. We identified strategies that were widely implemented, but that physicians viewed as less useful than other approaches with less uptake. For example, a high proportion of officebased physicians indicated that it is useful to receive staff support with EHR tasks, but only 35\% regularly receive assistance with their inbox. Similarly, practices can support physicians in implementing personal changes that are reported to be helpful. Areas for future research include assessing the impact of these strategies on burnout and clinician retention, as well as the return on investment of implementing these changes, particularly for small practices or those with fewer resources. Another key topic for future research is to identify additional strategies that may be effective in improving physicians' experience with HIT.

\section{Clinical Relevance Statement}

Most physicians in this statewide sample reported that both they personally and their practices had implemented strategies to improve their experience with health information technology. Physicians reported that useful strategies included improvements to the usability of the EHR(e.g., customizing the EHR and touch screen functionality) and additional staff support with EHR tasks and documentation. Prioritizing strategies that physicians find "actually useful" is critical, as many physicians in both office- and hospital-based settings reported reducing clinical hours to improve their experience.

\section{Protection of Human and Animal Subjects}

Human and/or animal subjects were not included in the study. The authors analyzed a de-identified dataset, which was available from RIDOH with a data use agreement.

\section{Author Contributions}

J.H. analyzed the data. All authors contributed to the design of the study, interpreted the data, and participated in the writing and review of the manuscript.

\section{Funding}

None.

\section{Conflict of Interest}

None declared.

\section{Acknowledgment}

The authors thank Samara Viner-Brown at the Rhode Island Department of Health for stewardship of the Rhode Island Health Information Technology survey for over 10 years.

\section{References}

1 Office of the National Coordinator for Health Information Technology. Non-federal acute care hospital electronic health record adoption, Health IT Quick-Stat 47. September 2017. Accessed October 2, 2020 at: https://dashboard.healthit.gov/quickstats/ pages/FIG-Hospital-EHR-Adoption.php

2 Office of the National Coordinator for Health Information Technology. Office-based physician electronic health record adoption, Health IT Quick-Stat \#50. January 2019. Accessed October 2, 2020 at: https://dashboard.healthit.gov/quickstats/pages/physicianehr-adoption-trends.php

3 Nguyen L, Bellucci E, Nguyen LT. Electronic health records implementation: an evaluation of information system impact and contingency factors. Int J Med Inform 2014;83(11):779-796

4 Hessels A, Flynn L, Cimiotti JP, Bakken S, Gershon R. Impact of heath information technology on the quality of patient care. Online J Nurs Inform 2015;19. Accessed June 15, 2021 at http:// www.himss.org/impact-heath-information-technology-qualitypatient-care

5 Riordan F, McHugh SM, O'Donovan C, Mtshede MN, Kearney PM. The role of physician and practice characteristics in the quality of diabetes management in primary care: systematic review and meta-analysis. J Gen Intern Med 2020;35(06):1836-1848

6 Moja L, Kwag KH, Lytras T, et al. Effectiveness of computerized decision support systems linked to electronic health records: a systematic review and meta-analysis. Am J Public Health 2014; 104(12):e12-e22

7 Murphy ZR, Wang J, Boland MV. Association of electronic health record use above meaningful use thresholds with hospital quality and safety outcomes. JAMA Netw Open 2020;3(09):e2012529

8 Yanamadala S, Morrison D, Curtin C, McDonald K, HernandezBoussard T. Electronic health records and quality of care: an 
observational study modeling impact on mortality, readmissions, and complications. Medicine (Baltimore) 2016;95(19):e3332

9 Friedberg MW, Chen PG, Van Busum KR, et al. Factors affecting physician professional satisfaction and their implications for patient care, health systems, and health policy. Rand Health Q 2014;3(04):1

10 Marmor RA, Clay B, Millen M, Savides TJ, Longhurst CA. The impact of physician EHR usage on patient satisfaction. Appl Clin Inform 2018;9(01):11-14

11 Walker-Czyz A. The impact of an integrated electronic health record adoption on nursing care quality. J Nurs Adm 2016;46(78):366-372

12 Pelland KD, Baier RR, Gardner RL. "It's like texting at the dinner table": a qualitative analysis of the impact of electronic health records on patient-physician interaction in hospitals. J Innov Health Inform 2017;24(02):894

13 Murphy DR, Meyer AN, Russo E, Sittig DF, Wei L, Singh H. The burden of inbox notifications in commercial electronic health records. JAMA Intern Med 2016;176(04):559-560

14 Baron RJ. What's keeping us so busy in primary care? A snapshot from one practice. N Engl J Med 2010;362(17):1632-1636

15 Gardner RL, Cooper E, Haskell J, et al. Physician stress and burnout: the impact of health information technology. J Am Med Inform Assoc 2019;26(02):106-114

16 Young RA, Burge SK, Kumar KA, Wilson JM, Ortiz DF. A timemotion study of primary care physicians' work in the electronic health record era. Fam Med 2018;50(02):91-99

17 Melnick ER, Dyrbye LN, Sinsky CA, et al. The association between perceived electronic health record usability and professional burnout among US physicians. Mayo Clin Proc 2020;95(03): 476-487

18 Payne TH, Corley S, Cullen TA, et al. Report of the AMIA EHR-2020 Task Force on the status and future direction of EHRs. J Am Med Inform Assoc 2015;22(05):1102-1110

19 Lee JS, Karliner LS, Julian KA, Linzer M, Feldman MD. Change in faculty perceptions of burnout and work life in an academic general medicine clinic: a pre-post study. J Gen Intern Med 2019;34(10):1973-1974

20 Gidwani R, Nguyen C, Kofoed A, et al. Impact of scribes on physician satisfaction, patient satisfaction, and charting efficiency: a randomized controlled trial. Ann Fam Med 2017;15(05):427-433

21 Bain PA. How physicians can save 56 H per year. WMJ 2017;116 (02):52

22 Ashton M. Getting rid of stupid stuff. N Engl J Med 2018;379(19): 1789-1791

23 Kadish SS, Mayer EL, Jackman DM, et al. Implementation to optimization: a tailored, data-driven approach to improve provider efficiency and confidence in use of the electronic medical record. J Oncol Pract 2018;14(07):e421-e428

24 Robinson KE, Kersey JA. Novel electronic health record (EHR) education intervention in large healthcare organization improves quality, efficiency, time, and impact on burnout. Medicine (Baltimore) 2018;97(38):e12319

25 Panagioti M, Panagopoulou E, Bower P, et al. Controlled interventions to reduce burnout in physicians: a systematic review and meta-analysis. JAMA Intern Med 2017;177(02):195-205

26 De Simone S, Vargas M, Servillo G. Organizational strategies to reduce physician burnout: a systematic review and meta-analysis. Aging Clin Exp Res 2019. Doi: 10.1007/s40520-019-01368-3

27 Kutney-Lee A, Sloane DM, Bowles KH, Burns LR, Aiken LH. Electronic health record adoption and nurse reports of usability and quality of care: the role of work environment. Appl Clin Inform 2019;10(01):129-139

28 Mandeville B, Cooper E, Haskell J, Viner-Brown S, Gardner RL. Use of health information technology by Rhode Island physicians and advanced practice providers, 2019. R I Med J (2013) 2020;103 (01):21-24

29 Gordon SH, Baier RR, Gardner RL. Primary care physicians' use of electronic health records in Rhode Island: 2009-2014. R I Med J (2013) 2015;98(10):29-32

30 Cooper E, Baier R, Morphis B, Viner-Brown S, Gardner R. HIT implementation by Rhode Island physicians, advanced practice registered nurses and physician assistants, 2014. R I Med J (2013) 2014;97(10):57-59

31 Pelland K, Baier R, Morphis B, Viner-Brown S, Gardner R. Health information technology (HIT) adoption and use by Rhode Island advance practice registered nurses and physician assistants, 2013. R I Med J (2013) 2013;96(12):48-49

32 Baier RR, Gardner RL, Buechner JS, Harris Y, Viner-Brown S, Gifford DS. Creating a survey to assess physicians' adoption of health information technology. Med Care Res Rev 2012;69(02):231-245

33 Baier R, Voss R, Morphis B, Viner-Brown S, Gardner R. Rhode Island physicians' health information technology (HIT) use, 20092011. Med Health R I 2011;94(07):215-217

34 Baier R, Buechner J, Gifford D, Harris Y, Gardner R. The adoption and use of health information technology (HIT) by Rhode Island physicians, 2009. Med Health R I 2010;93(03):89-90

35 SurveyMonkey, San Mateo, California. Accessed 2021 at: https:// www.surveymonkey.com/mp/aboutus/office-locations/

36 Kroth PJ, Morioka-Douglas N, Veres S, et al. The electronic elephant in the room: Physicians and the electronic health record. JAMIA Open 2018;1(01):49-56

37 Rhode Island Department of Health. Results from the physician health information technology survey [powerpoint slides]. HIT data sharing meeting. 21 Nov 2019. Accessed August 17, 2020 at: https://opengov.sos.ri.gov/Common/DownloadMeetingFiles?FilePath $=\mid$ Minutes $|1293| 2020 \mid 370950 . p d f$

38 DeChant PF, Acs A, Rhee KB, et al. Effect of organization-directed workplace interventions on physician burnout: a systematic review. Mayo Clin Proc Innov Qual Outcomes 2019;3(04):384-408

39 Thomas Craig KJ, Willis VC, Gruen D, Rhee K, Jackson GP. The burden of the digital environment: a systematic review on organization-directed workplace interventions to mitigate physician burnout. J Am Med Inform Assoc 2021;28(05):985-997

40 Tsai CH, Eghdam A, Davoody N, Wright G, Flowerday S, Koch S. Effects of electronic health record implementation and barriers to adoption and use: a scoping review and qualitative analysis of the content. Life (Basel) 2020;10(12):327

41 Arndt BG, Beasley JW, Watkinson MD, et al. Tethered to the EHR: primary care physician workload assessment using EHR event log data and time-motion observations. Ann Fam Med 2017;15(05): 419-426

42 Dymek C, Kim B, Melton GB, Payne TH, Singh H, Hsiao CJ. Building the evidence-base to reduce electronic health record-related clinician burden. J Am Med Inform Assoc 2020. Doi: 10.1093/jamia/ocaa238

43 Hilliard RW, Haskell J, Gardner RL. Are specific elements of electronic health record use associated with clinician burnout more than others? J Am Med Inform Assoc 2020;27(09):1401-1410

44 Sinsky CA, Dyrbye LN, West CP, Satele D, Tutty M, Shanafelt TD. Professional satisfaction and the career plans of US physicians. Mayo Clin Proc 2017;92(11):1625-1635

45 Tai-Seale M, Dillon EC, Yang Y, et al. Physicians' well-being linked to in-basket messages generated by algorithms in electronic health records. Health Aff (Millwood) 2019;38(07):1073-1078

46 Shanafelt T, Goh J, Sinsky C. The business case for investing in physician well-being. JAMA Intern Med 2017;177(12):1826-1832

47 Brtnikova M, Crane LA, Allison MA, Hurley LP, Beaty BL, Kempe A. A method for achieving high response rates in national surveys of U.S. primary care physicians. PLoS One 2018;13(08):e202755 